\title{
Craniovertebral Junction Chordomas
}

\author{
Pratipal Kalsi and David Choi \\ National Hospital for Neurology E Neurosurgery, London \\ United Kingdom
}

\section{Introduction}

Chordomas are rare tumours that arise from remnants of the embryonic notochord. They can be located in all places where the notocord existed, such as the nasopharynx, clivus, sella turcica, foramen magnum, cervical spine and sacrococcygeal region. This chapter will focus on chordomas affecting the craniovertebral junction $(\mathrm{CV})$. Chordomas are rare malignant tumours with an incidence of less than 1 per 100,000. The site of origin of skull base chordomas is usually the clivus and from here they can extend into the anterior fossa, middle fossa, the sellar and parasellar regions, and through the foramen magnum into the upper cervical spine. In the majority of cases the typical histological appearances and characteristic location of chordomas render the diagnosis straightforward. The symptoms and signs are highly variable and depend on the exact site of the lesion and the involvement of adjacent structures. These can range from cranial nerve palsies, motor and sensory deficits, to gait disturbance and balance problems. Radiological diagnosis of craniovertebral junction chordomas has improved with the advent of modern CT and MR imaging modalities and tumour location and extent of skull base involvement can be precisely defined. Surgery is the most effective form of treatment for patients with craniovertebral junction chordomas and radical resection augmented with adjuvant therapies such as proton beam therapy have been shown to prolong survival. Although chordomas are usually slow-growing tumours they are locally aggressive with a tendency to infiltrate adjacent tissues and organs. Local recurrence is common and often causes death. Metastasis is well documented but is uncommon. This chapter will aim to give an overview of the diagnosis and management of $\mathrm{CV}$ junction chordomas.

\section{Epidemiology}

Chordomas are rare tumours arising from persistent rests of notochordal remnants. They constitute $0.2 \%$ of all CNS tumours. Chordomas represent between $1 \%$ to $8 \%$ of primary malignant bone tumours and $20 \%$ of those arising from the spine. (Rosenberg AE, 2003) The age adjusted incidence for chordomas is 0.08 per 100000 .

There is a 2:1 male preponderance for all chordomas. However, CV junction chordomas have a more equal sex distribution. There is a strikingly low incidence in ethnic minorities and the incidence in African Americans is around quarter of that in white populations.

These tumours tend to occur across a wide age range and the peak incidence varies with anatomical location. Chordomas of the $\mathrm{CV}$ junction present more commonly during the fourth and fifth decades with the average age at diagnosis being 38 years. They generally 
present at a younger age than sacral and vertebral chordomas. In comparison, sacral chordomas tend to present at an older age, with the average age of presentation being 56 years.

Small series of childhood chordomas have been reported and these are usually found at the skull base. However, they account for less than $5 \%$ of all chordomas. Familial chordoma has been described but is extremely rare and several chromosomal loci have been identified including 7q33 and isochromosome 1q. (Bhadra \& Casey, 2006)

\section{Embryology \& genetics}

Chordomas arise from remnants of the embryonic notochord and are located in all places where the notocord existed, including the clivus, sella turcica, foramen magnum, upper cervical spine and nasopharynx.

The notochord is a rod-like structure which comprises the embryonic axis of the body. It arises from ectodermal cells and forms during the third week of life. It is known to have an important role in the development of the vertebral column and is thought to play a part in somite differentiation, vertebral chondrogenesis and vertebral column segmentation as well as other possible roles. (Fleming et al., 2001)

During fetal life the notochord regresses but at the site of the intervertebral discs it persists and contributes to the formation of the nucleus pulposus. (Pazzaglia et al., 1989)

There is a large amount of evidence to support the theory that chordomas arise from notochordal cells. Portions of the notochord are known to persist at a number of sites including the skull base, coccyx and spine. These small, well-circumscribed, gelatinous collections of cells were first described by Muller, as ecchordoses physaliphoria. (Muller $\mathrm{H}$, 1858) There is a morphological similarity between the cells of chordomas and ecchordoses physaliphoria. (Ribbert H, 1895) The immunohistological similarity between chordomas and notochord cells has been demonstrated in a number of studies. In addition, a study by Salisbury et al. (1993) demonstrated that although the notochord is a rod-like structure the rostral and caudal ends of the notochord are more complicated structures that demonstrate forking at the ends with fragments of chordal tissue separate from the main bulk of the notochord. This anatomical feature may help explain why regression of the notochord in fetal life may leave behind collections of notochordal cells which may subsequently give rise to chordomas in the common sites such as the skull base and sacrococcygeal region. (Salisbury et al., 1993)

Cytogenetic studies of chordoma show a number of abnormalities including triploidy, marker chromosomes, losses of or from chromosomes 1,3,4,10 and 13, and gains of chromosomes 7 and 20. (DeFrancesco et al., 2006) Microsatellite instability resulting from DNA mismatch repair deficiencies has also been demonstrated. (Klingler et al., 2000) However, no chordoma-specific translocations have yet been identified.

\section{Pathology}

Chordomas are typically found in three locations in the spine, with $50 \%$ occurring in the sacrum. The second most common site is the clivus, accounting for $35 \%$ of tumours and they 
are also seen less commonly in any part of the vertebral column. Other intraaxial and extraxial sites have been reported in the literature.

The site of origin of skull base chordomas is the clivus. From here they can extend into the anterior fossa, middle fossa, the sellar and parasellar regions and through the foramen magnum into the upper cervical spine. In the majority of cases the typical histological appearances and characteristic location of chordomas renders the diagnosis straightforward.

Chordomas are typically multilobulated masses. They are soft and gelatinous with a welldefined, greyish surface. The cut surface is usually homogenous but calcifications and occasional haemorrhages may be seen. However, chordomas are not histologially encapsulated and extensions of the fibrous tissue on the surface penetrate the tumour as fibrous septa creating a lobular appearance.

Microscopically chordomas are composed of relatively uniform populations of cells with cytoplasmic vacuoles of varying sizes. This abundant cell type is the pathognomic physaliphorous cells, while some cells have signet ring morphology and others have a more eosinophilic cytoplasm. The tumour cells are embedded in an basophilic and mucinous matrix. The cell nuclei are usually small, round or oval, with a dense chromatin pattern but occasional tumours may contain focal pleomorphism. Mitoses, although present, are usually rare. Mild atypia may be present but necrosis is uncommon. (Figure 1)

The cells of chordomas contain glycogen, and the matrix stains positively with mucicarmine and Alcian blue and metachromatically with toluidine blue. Ultrastructural examination of chordomas shows evidence of epithelial differentiation, with the presence of cell junctions and intracytoplasmic connections. Membrane-bound glycogen, intermediate filaments and rough endoplasmic reticululm are also found.

Chordomas stain positive for a number of immunohistochemial markers including positivity for cytokeratins, EMA, vimentin and occasionally S100 protein and carcinoembryonic antigen. Brachyury expression can also be used to distinguish them from other tumours such as chondrosarcoma. However, actin, demin, CD31, CD34 and collagen are usually negative. (DeFrancesco et al., 2006)

Variations of chordomas containing cartilaginous tissue have been described as chondroid chordomas. These account for a third of clival chordomas, have a slight female preponderance and occur in a younger age group. Those containing areas of sarcoma are described as dedifferentiated chordomas and they have a high risk of metastasis and a poor prognosis. The dedifferentiated component is usually not seen at presentation but occurs after recurrences and sometimes radiotherapy.

A few other lesions can mimic the appearance of chordoma on histology. These include chordoid meningioma, chondroma, chondrosarcoma (Figure 2), melanoma and metastatic adenocarcinoma. However, these lesions can usually be differentiated using further laboratory techniques.

\section{Symptoms and signs}

The craniovertebral region is a vital entry and exit point for a number of important neural pathways and structures. The precise nature of these clinical features and symptom 
progression depends entirely on the location of the chordoma and the rapidity of growth into the vital adjacent structures. It is therefore imperative that a thorough clinical history and clinical examination are undertaken to elucidate as much clinical information as possible at the time of diagnosis.
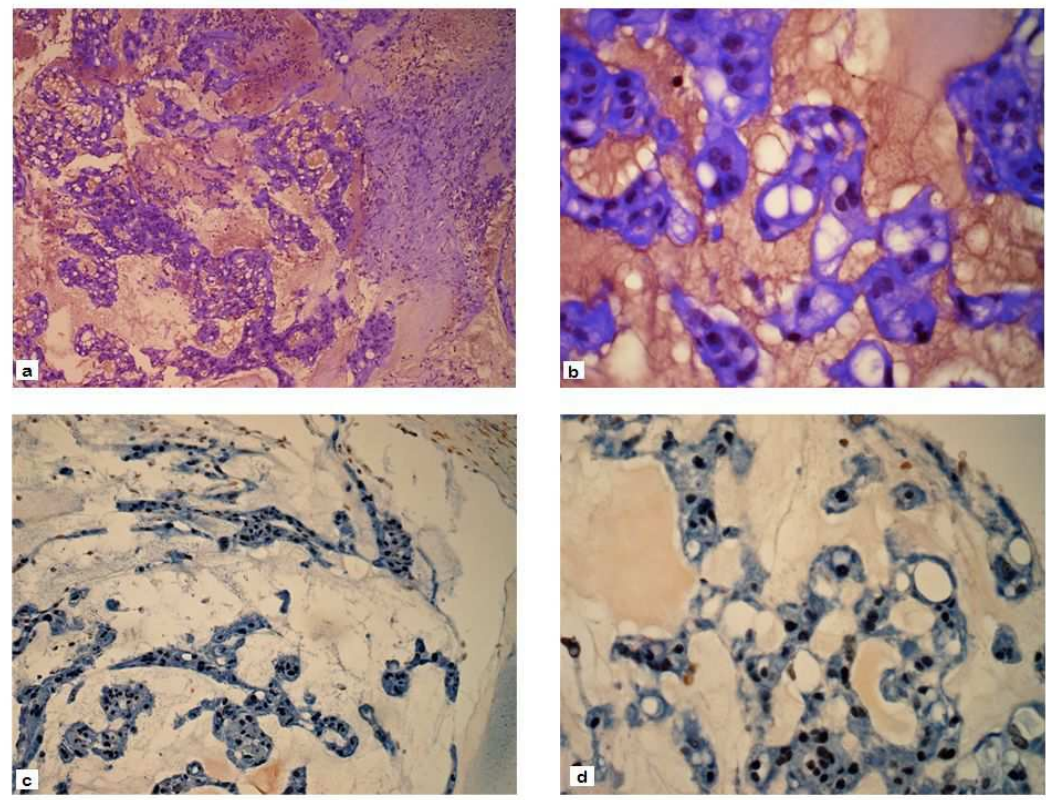

Fig. 1. a\&b) H\&E staining showing characteristic features of a chordoma ( $x 40 \& x 100)$. Typical sheets of cells with cells containing vacuoles of various sizes can be seen. At higher magnification the phylasipharous cell, with it's large vaculole, can be easily made out as the abundant cell type. c\&d) Brachyury immunohistochemistry identifying the characteristic chordoma cells.

Patients with chordomas at the CV junction can present in a number of ways including symptoms and signs of central and peripheral nervous system dysfunction. Clinical features can include sensory or motor disturbances, problems with gait, proprioception, coordination and respiratory compromise.

Neck pain is a presenting feature in $86 \%$ of patients. (Choi et al., 2010) Pain may occur in a dermatomal distribution, especially if the $\mathrm{C} 2$ nerve root is involved, but this is not always the case. Due to the propensity of chordomas to cause bone destruction the neck pain is usually non-specific and can sometimes be attributed to degenerative changes, particularly in older patients who do not have other features suggestive of more sinister disease at this location. Myelopathy is a common presenting feature, present in $18.6 \%$ of patients (Choi et al., 2010) and this may lead to weakness of the hands and associated spasticity of the extremities due to compression of the corticospinal tracts. (Crockard et al., 1993) Rarely a syrinx may be a present and these patients may present with atrophy of upper limb muscles and sensory disturbances. 


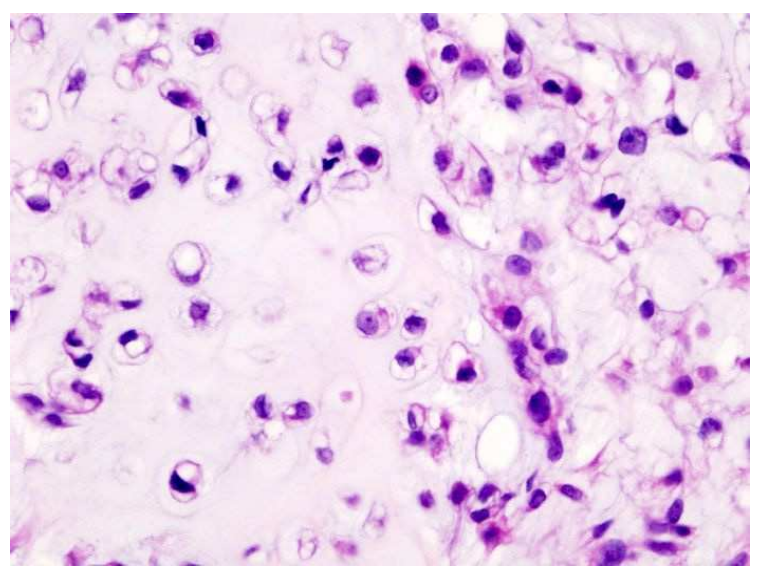

Fig. 2. H\&E staining demonstrating chondrosarcoma (x100). The cells are not always arranged in a dense sheet like manner and contain less vacuoles and no phylasipharous cell. However, there are different grades of chondrosarcoma, which can all have slightly different appearances which need to be distinguished from chordoma using immunohistochemistry.

A number of cranial nerve deficits can result from chordomas at this location. Compression of the pons, medulla and rostral cervical region can lead to dysfunction of the trigeminal nucleus. In addition some branches of the facial, glossopharyngeal and vagus nerves supplying sensation to the face and tongue may also be affected as well as the motor supply to the palate. In addition, the accessory nerve may be compressed as it travels through the foramen magnum leading to motor deficits of the sternocleidomastoid and trapezius muscles. Chordomas located at the ventral surface of the foramen magnum may lead to compression of the hypoglossal nerve, which leads to ipsilateral tongue dysfunction and atrophy. If the jugular foramen is involved by the spread of chordoma then a number of distinct neurological syndromes may arise including Vernets, Collet-Sicard amd Villaret Syndromes. (Svien et al., 1969)

\section{Imaging}

Radiological diagnosis of $\mathrm{CV}$ junction chordomas has improved with advent of modern imaging modalities. Tumour location and extent of skull base involvement can now be precisely defined. Computed tomography (CT) and Magnetic Resonance Imaging (MRI) provide the mainstay of diagnostic information. However, plain radiographs, especially lateral radiographs of the cervical spine also have an important role to play, particularly in the postoperative assessment of cervical spine instrumentation. (Figures $3 a \& b$ )

High resolution CT of the CV junction with bone and soft-tissue windows is very sensitive for detecting chordomas of the craniocervical junction. Fine cut axial and coronal unenhanced and contrast enhanced CT can evaluate bone involvement. On a CT scan, intracranial chordoma has a characteristic appearance with tumours being centrally located, well-defined, soft tissue masses arising from the clivus and causing lytic bone destruction. (Figure 4) Chordomas are usually hyper attenuating lesions and on administration of intravenous contrast they show a degree of enhancement. 

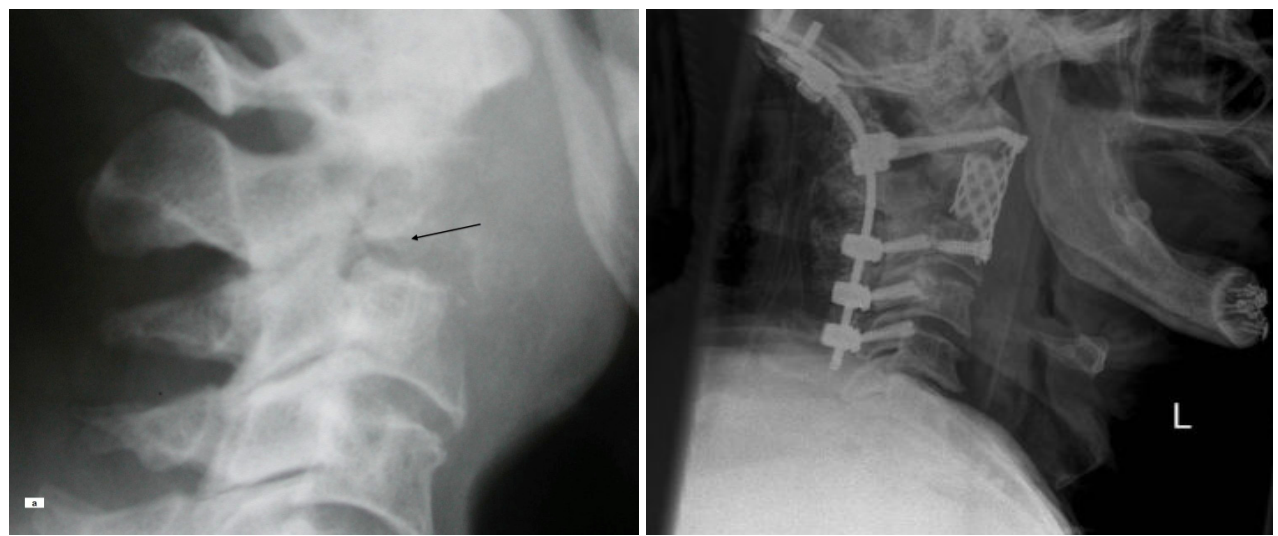

Fig. 3. a) Plain cervical spine lateral radiograph demonstrating osteolytic bone destruction in the region of the odontoid peg (arrow). The chordoma mass can be seen anterior to the osteolyitc bone destruction, pushing the pharyngeal tissues anteriorly b) Post-operative plain cervical spine radiograph showing $\mathrm{C} 2$ corpectomy with insertion of cage and instrumented occipitocervical fusion using screws and rod fixation system.

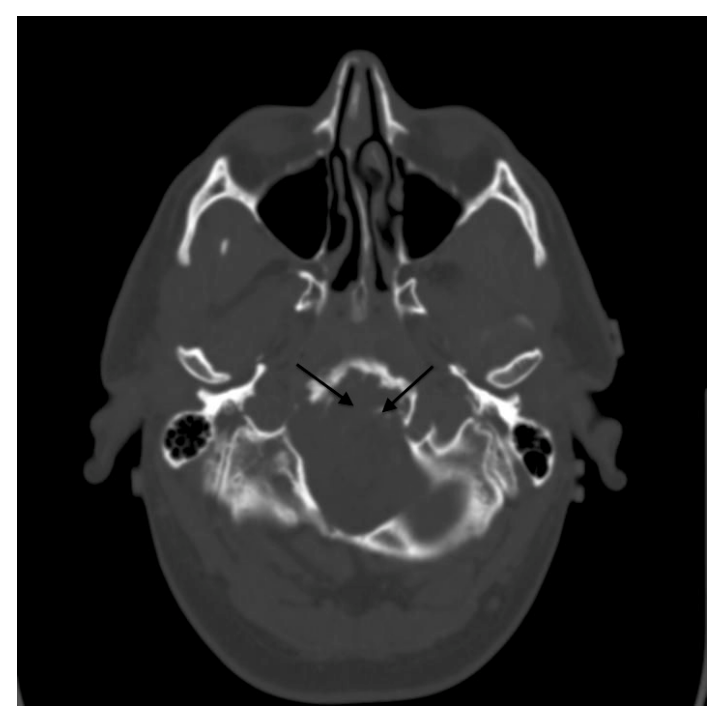

Fig. 4. Non-contrast enhanced axial CT of the craniovertebral junction, showing lytic bone destruction of the anterior clivus (arrows).

MRI of the CV junction is the best modality for evaluation of craniocervical junction chordomas. MR defines the extent of the tumour and it's spread to adjacent structures and is therefore useful both for diagnosis and for preoperative planning. Sagital images are the most useful as they define the posterior margin of the tumour and importantly, the relation to the brainstem and the nasopharyngeal extension of the chordoma. (Figures $5 \mathrm{a} \& \mathrm{~b}$ ) Axial and coronal images are useful in detecting extension into surrounding structures. 

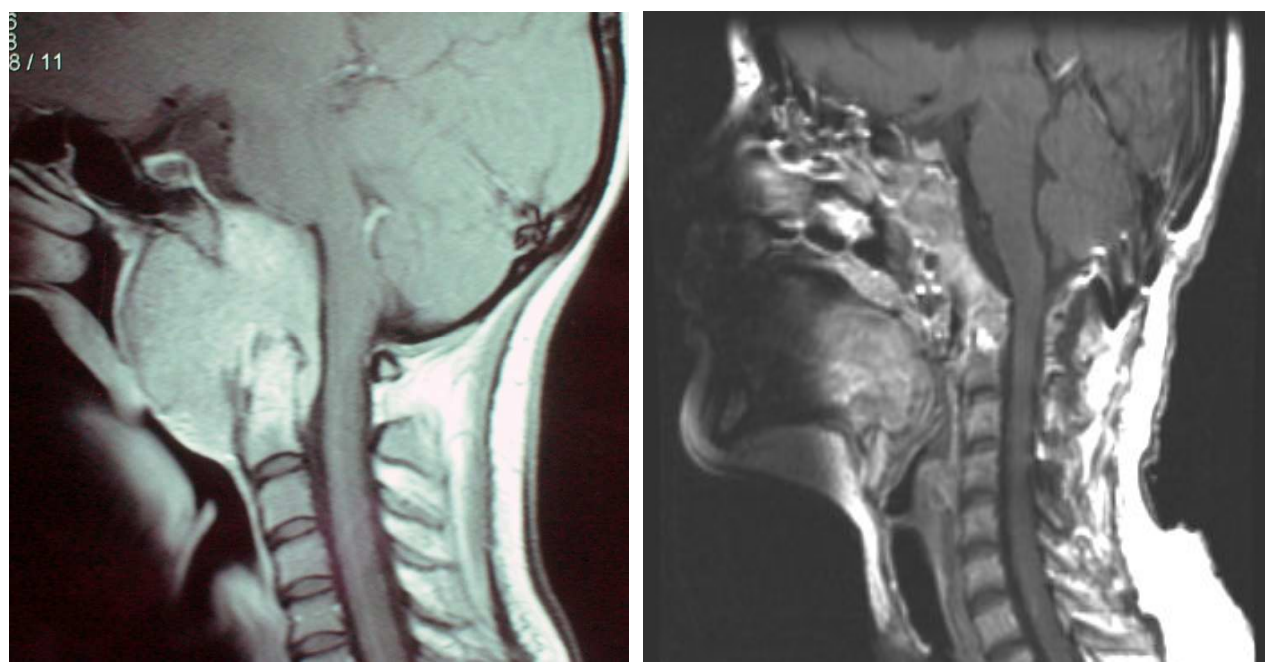

Fig. 5. a) Pre-operative T1 weighted sagital MRI showing extensive chordoma affecting the craniovetebral junction and spreading anteriorly to displace the pharyngeal structures. The tumour has a high signal and tumour expansion into the surrounding structures can be well delineated. b) Post-operative T1 weighted MRI of the craniovertebral junction showing resection of the tumour.

On T1 weighted MR imaging, chordomas usually demonstrate low signal intensity. Areas of high signal may be seen on T1 weighted images and these usually represent areas of focal haemorrhage. Chordomas classically have a high signal on T2-weighted MR scans due to their high fluid content. In addition T2 imaging is excellent for delineating the tumour from adjacent structures.

Craniovertebral junction chordomas demonstrate a degree of enhancement with gadolinium contrast. The enhancement is sometimes described as a 'honeycomb' appearance, which is due to intratumoural areas of low signal intensity. Fat suppression sequences can be used to differentiate tumour margins from adjacent fatty bone marrow. Small intraclival chordomas may be better demonstrated with these sequences.

MR Angiography (MRA) has a role in demonstrating the patency of the basilar artery as well as involvement of other large vessels including the internal carotid artery, which may be involved in large craniovertebral junction chordomas with significant anterior extension. Chordomas in this region often displace or encase vessels in this region and MRA has an advantage over digital subtraction angiography (DSA), which does not allow detection of encasement without luminal narrowing or occlusion. MRA is usually sufficient in preoperative planning but DSA can demonstrate the collateral circulation and allow balloon occlusion of the internal carotid to help determine whether a patient is at risk if an important vessel is sacrificed.

Local recurrence of these tumours is a common finding and gadolinium enhanced MR is the best mode of assessing the degree of tumour excision and for follow-up. Marked high signal on T2 weighted imaging suggests tumour recurrence rather than post-operative changes. 
The lesions most often confused with craniovertebral junction chordomas are chondroscarcomas. Although the majority of these usually occur in or around the sutures of the petrous bone, they can sometimes arise from the midline and mimic the MR appearance of a chordoma. Meningiomas arising from the clival region often do not cause bony destruction and tend to have a characteristic dural attachment.

\subsection{Illustrative case}

A 42-year-old man presented with a two-year history of neck pain, progressive difficulty in swallowing and visual disturbance. He had no significant medical problems and no family history of any illness. On examination he was alert and orientated in time, place and person. The only neurological deficit he had a left occulomotor and abducens nerve palsy. Plain radiographs of his cervical spine were unremarkable. Non-enhanced CT scan showed a lytic destruction of the anterior clivus (Figure 4). MR imaging was subsequently performed. The non-enhanced sagital T1-weighted MRI (Figure 5) demonstrated a large homogenous mass arising from the region of the craniovertebral junction and extending anteriorly compressing the pharyngeal structures. There is also associated lytic change within the odontoid peg. It was decided that the patient should have surgery to debulk the tumour followed by adjuvant radiation treatment. (See below)

\section{Treatment}

Harvey Cushing was the first surgeon to remove a chordoma successfully. (Cushing, 1912) Chordomas are usually extradural tumours that are found in the midline but they often extend into surrounding regions. There is a large body of evidence to suggest that maximal tumour resection is associated with a better outcome.

A number of approaches for the treatment of craniovertebral junction chordomas have been described but the most commonly used surgical approaches for lesions of the lower clivus, foramen magnum and the upper cervical spine is the standard transoral approach. A number of extended anterior midline transoral approaches exist including a transoral approach with a palatotomy, an 'open-door' maxillotomy, transmandibular and midface degloving procedures but the approach used depends on the exact site and extent of the lesion and surgeon experience and preference. More recently, endoscopic trans-nasal approaches have also been used with success.

All of the above approaches are suitable for midline clival chordomas but where there is significant lateral extension the midline approach alone may be insufficient for the removal of the entire tumour and more complex lateral approaches may have to be used as a primary or secondary procedure. A number of these approaches have been described for tumours of the upper clivus and include the subtemporal, transcavernous and the transpetrous approaches. (Gay et al., 1995a) For lateral lesions of the midclivus a subtemporal and infratemporal approach have been described. For lesions of the lower clivus with lateral extension to the occipital condyle and jugular foramen, the extreme lateral transcondylar approach can be used. (Sen \& Sekhar, 1990) Larger chordomas involving the entire clival region, the sphenoid and the sellar region with extension anteriorly to the optic nerves may need staged surgery via multiple approaches. 


\subsection{Surgical approaches}

The standard transoral approach is the main authors preferred approach to ventral midline craniocervical junction chordomas. It was first described by Kanavel (1908) who used it to remove a bullet between the skull base and atlas. This approach has since been modified and used to treat a number of aetiologies. (Kanavel, 1908) The standard transoral approach is the most frequently used approach for resecting chordomas of the craniocervical junction in the region of the lower clivus down to the level of $\mathrm{C} 2$. It may be combined with a soft palate split or an 'open-door' maxillotomy. Upper clival lesions may be excised using endoscopic trans-nasal techniques, which may have a lower complication rate than the 'open-door maxillotomy'.

Prior to performing the transoral procedure it is essential to ensure that the maximal interdental opening is greater than $25 \mathrm{~mm}$. A nasotracheal intubation is preferred and a nasogastric tube must be inserted. This ensures that the stomach is decompressed and more importantly, allows the administration of enteral nutrition following the procedure yet allowing the oropharyngeal wounds to heal. The patient's head is placed in a Mayfield head holder with the patient supine in the head-up position. The mouth is then cleaned with antiseptic solution, topical hydrocortisone applied to the mouth and oropharynx to reduce post-operative inflammation and parenteral antibiotics administered preoperatively and a further two doses following surgery.

The transoral retractor is inserted and the tongue blade ensures that the tongue is pushed down and out of the way. Insertion of the palatal retractors ensures that the palate is pulled upwards in the opposite direction and the nasotracheal and nasogastric tubes are pulled clear of the surgical field. The surgical anatomical landmark is the anterior tubercle of $\mathrm{C} 1$, to which is attached the anterior longitudinal ligament and the overlying longus colli muscle. A midline vertical incision is made on the tubercle of $\mathrm{C} 1$ and the pharyngeal retractors inserted and the longus colli muscle and the anterior longitudinal ligament cut using monopolar diathermy. This reveals the arch of $\mathrm{C} 1$ and the odontoid peg. The extent of the chordoma however, will dictate the craniocaudal and lateral extent of the exposure, and care should be taken to avoid damage to the hypoglossal nerve and the vertebral artery laterally. The $\mathrm{C} 1$ anterior arch and the peg are drilled out and the inferior clivus can be removed with drill and Kerisson rongeurs. The dural basilar plexus must be carefully dissected off the inferior border of the clivus to prevent vascular injury and bleeding. From here chordoma affecting the clivus can be resected. (Bouramas \& Crockard, 2003)

If necessary the soft palate can be split in the midline to extend the superior and lateral exposure and this allows greater visualisation and access to the lower clivus. Another modification of the transoral procedure combines a LeFort I osteotomy with a midline incision in the hard and soft palate, the so-called 'open-door' maxillotomy. This provides excellent exposure to the upper middle clivus and sphenoid and gives good exposure inferiorly and laterally. For unilaterally extending tumours a unilateral LeFort osteotomy can be performed.

The endoscopic transnasal approach was developed to provide access to lesions of the middle and upper clivus and provides excellent visualization craniocervical junction. At the same time it avoids the complications of the traditional transoral approach and significantly reduces the morbidity associated with a LeFort osteotomy with 'open-door' maxillotomy. After the patient has undergone preoperative planning and the nasal anatomy has been 
assessed, the patient is put in a Mayfield head holder and topical adrenaline is applied to the nasal septum and mucosa of the turbinate bones. The entire procedure is performed under direct visualisation using an endoscope. The posterior aspect of the nasal septum is perforated near the rostrum of the sphenoid sinus to provide access to the nasopharynx. The rostrum of the sphenoid sinus is opened and the vomer and floor of the sphenoid sinus are removed. The mucosa of the nasophrynx is incised and usually reflected downwards into the oropaharynx and can be used as a flap at the end of the procedure. This allows visualisation of the anterior arch of $\mathrm{C} 1$ and the odontoid and resection of the tumour can then be performed. (Kassam et al., 2005)

Following an anterior approach to debulk the tumour a posterior occipito-cervical fixation is often required to provide stability to the upper cervical spine.

\subsection{Surgical complications}

A number of series have demonstrated high complication rates from excision of craniocervical junction chordomas. Harbour et al. (1991) reported 3 postoperative deaths in a series of 11 patients. Carpentier et al. (2002) reported 3 perioperative deaths in a series of 36 patients. Gay et al. (1995b) had a CSF leak rate of 30\% and Pallini et al. (2003) reported 17 significant complications in 26 patients including 3 CSF fistulae. Choi et al. (2010) had a CSF leak rate of $6.2 \%$ and other complication rates included dysphagia $(3.1 \%)$, nasal regurgitation $(3.1 \%)$, meningitis $(3.1 \%)$, sepsis $(3.1 \%)$, chest infections, cranial nerve deficits and fixation failure. In the study by Choi et al. (2010), there were no differences in sepsis rates when comparing the standard transoral with the more extensive procedures. The study also showed that patients having the more extended surgeries appeared to have a worse prognosis than the standard transoral approach, although this was not statistically significant. It was also noted that patients who had their primary surgery at the specialist centres had a better outcome than those patients who had been initially treated elsewhere and had been referred on recurrence. Nasal regurgitation was more common with opendoor maxillotomies than the standard procedure but the incidence of nasal regurgitation was not significantly different following division of the soft palate. Dysphagia was more common with mandibulotomy and glossotomy. (Choi et al., 2010)

It is clear that surgery confers a better survival benefit than with conservative treatment. Erikson et al. (1981) showed that survival rate for 11 patients with untreated chordoma was only 1 year. Radical resection of the tumour appears to confer the best survival outcomes as previously stipulated by Crockard et al. (2001) and also demonstrated by the large series of Choi et al. (2010). Colly \& Al-Mefty (2001) achieved complete tumour excision in almost half of their patients with greater than ninety percent in almost $80 \%$. However, they had a complication rate approaching 60\%, with predominantly neurologic complications including cranial nerve palsies, cerebrospinal fluid leak, hydrocephalus, meningitis and oronasal fistulae. However, they found that complication rates did not greatly increase with greater extents of resection but there is a correlation of better survival with greater than $90 \%$ tumour resection. Gay et al. (1995) also demonstrated that there was no difference in complication rates in those patients receiving complete excision and those receiving partial debulking procedures. Although true oncological resection of these tumours is virtually impossible, aggressive tumour resection, including removal of bone margins where possible to reduce tumour load does appear to confer a survival benefit. 


\section{Radiation therapy}

Despite the application of radiotherapy and radiosurgery for the treatment of $\mathrm{CV}$ junction chordomas, the importance of maximal surgical resection remains unequivocal. Greater survival has been shown to correlate with radical removal as opposed to partial resection. However, radical resection is not always possible due to the close proximity of these tumours to critical structures and the associated morbidity this entails. Traditionally chordomas have been regarded as relatively radio-resistant tumours but a number of treatment strategies using radiation treatments have been developed to gain control of these locally aggressive tumours. However, the size and precise location of the tumour is the most important factor in considering radiation planning.

Fractionated radiotherapy with high energy photons and radiotherapy with charged particles are the two most common forms of radiotherapy for $\mathrm{CV}$ junction chordomas. Fractionated radiotherapy has the benefit of sublethal damage repair of normal tissues in between treatment fractions, and thus the importance of surgery in resecting tumour from critical structures is vital.

\subsection{Conventional radiation therapy}

Conventional radiation therapy has been used for decades to gain local control of skull base chordomas and most patients undergo adjuvant fractionated radiotherapy to reduce the risk of tumour recurrence. However, initial doses of 50 to $55 \mathrm{~Gy}$ after resection did not provide successful local control and were associated with poor progression-free and overall survival rates. (Catton et al., 1996; Cummings et al., 1999) Catton et al reported on 13 patients who received a median dose of 50 Gy but only one of these patients remained disease free at 93 months following treatment. In the study by Cummings et al 24 patients diagnosed with chordoma were treated with megavoltage radiation therapy following incomplete tumour resection. The 5 year survival was $62 \%$ and at 10 years it was $28 \%$.

Conventional radiotherapy with high energy photons, ranging from 40-70 Gy in different series, has been shown to be of survival benefit compared to surgery alone. However, local recurrence rates after residual incomplete resection followed by photon radiation therapy have been reported between $80 \%$ to $100 \%$. (Catton et al., 1996; Cummings et al., 1999; Fuller \& Bloom, 2003; Zorlu et al., 2000)

Although higher doses of fractionated radiotherapy have been shown to reduce the rate of tumour recurrence and increase survival rates, administration of higher doses are associated with greater side effects. Subsequently, other forms of radiation therapy have been pursued to greater success.

\subsection{Proton beam radiation therapy}

The largest amount of data in the use of radiation therapy for CV junction chordomas relates to proton beam therapy. Radiotherapy with charged particles has been used with success in the treatment of these tumours and has the advantage that it has a steeper fall-off then conventional therapy. Proton radiation allows improved dose localization than conventional photon therapy. In addition the positive charge of protons allows a energy dependent finite range in tissues, and the energy deposition demonstrates a sudden rise in dose at the end of 
the range with a subsequent sharp fall-off to zero dose, thereby providing excellent dose localization. This is known as the Bragg peak effect. Protons are assumed to have a slightly higher relative biological effectiveness compared with conventional photon radiotherapy. Proton beam radiation therapy is not restricted to the size of the tumour.

There are three large centres which have reported their outcomes of proton beam therapy in the literature: Loma Linda University Medical Centre (Loma Linda, CA), Harvard Cyclotron Laboratory at Massachusettes General Hospital (MGH/HCL) (Cambridge, MA) and the Institut Curie, Centre Protontherapie d'Orsay (Orsay Cedex, France)

The first patient to undergo proton irradiation for a CV junction chordoma was in 1974 at MGH/HCL. Since then, techniques have been developed to provide high dose, fractionated radiotherapy in doses excess of $70 \mathrm{~Gy}$.

At LLUMC (Hug et al, 1999, 2001) Chordoma patients were treated with fractionated proton beam therapy to a mean dose of 70.7 CGE. The researchers observed a 3-year control rate of $67 \%$ with 5-year overall survival of 79\%. In 1999 the MGN/HCL published there results of 519 cases of skull base tumours, of which 290 were chordomas. These patients were treated with combined proton and photon technique. The 5- and 10-year local recurrence free survival rates were $64 \%$ and $42 \%$ respectively. (Muzenrider \& Liebsch, 1999) A hundred patients diagnosed with chordomas of the skull base and cervical spine were treated at the Centre de Protontherapie d'Orsay with a combined proton and photon technique. The median dose delivered to the tumour was 67 CGE. The 2- and 4-year local control rates were $86 \%$ and $54 \%$.

Another form of charged particle therapy is the use of carbon ions, which also has a steep dose fall off after the Bragg peak. At the Gessellschaft fur Schwerionenforschung Darmstadt center in Heidelberg, Germany 96 patients with skull base chordoma were treated with carbon ion therapy. (Schulz-Ertner et al., 2007) The median dose delivered was 60 CGE with a mean follow-up time of 31 months. At 3 years, the local control rate in this series was $81 \%$ and $70 \%$ at 5 -years. Overall survival rates were $92 \%$ and $89 \%$ at 3 - and 5-years respectively.

The superior local tumour control and overall survival achieved using proton beam over conventional photon radiotherapy are due to the superior dose localisation characteristics of protons that result in a higher dose of radiation being delivered. However, side effects of this radiation therapy are relatively common and include the typical early and late radiation sequelae including nausea, headaches and radiation necrosis of the brain. It is important to note that there have not been any randomised trials comparing proton beam therapy to other types of radiation treatment.

\subsection{Stereotactic radiosurgery}

Stereotactic radiosurgery is a technique which is designed to achieve a greater radiobiological effect than conventional forms of radiotherapy. Due to its precision and steep dose fall off, stereotactic radiosurgery has been used as a minimally invasive primary, adjuvant and palliative management option in patients with $\mathrm{CV}$ junction chordomas.

Stereotactic radiosurgery is a potent treatment option for small sized chordomas. The greatest benefit of stereotactic radiosurgery is the steep dose gradient achievable, which minimizes radiation outside the tumour target, thus allowing the delivery of a larger dose to the tumour without exceeding the radiation-related tolerance of normal tissues. 
The North American Gamma Knife Consortium (NAGKC) was established to evaluate the outcomes of patient with relatively rare tumours including chordomas. Their collaboration identified 71 patients who underwent stereotactic radiosurgery with Gamma Knife for chordoma. The median age of patients was 45 years and the median SRS target volume was $7.1 \mathrm{~cm} 3$ (range 0.9-109 $\mathrm{cm} 3$ ). Their study suggests that SRS is as effective as proton beam therapy for small tumours that have not been treated with prior radiation.

However, more rigorous studies need to be carried out to discover the relative merits of stereotactic radiosurgery over proton beam therapy.

For patients with craniocervical junction chordoma, maximal surgical resection with proton beam therapy remains the mainstay of treatment with stereotactic surgery possibly having a role in selected cases.

\section{Medical therapies}

Medical therapies do not routinely form the mainstay of treatment of chordomas. As with most other low grade malignancies these tumours are not reported to be sensitive to chemotherapy. A number of anecdotal reports of responses to chemotherapy exist (Azzarelli et al., 1988; McSweeney \& Sholl, 1959; Razis et al., 1974; Scimeca et al., 1996) but these are limited to case reports. A prospective phase II clinical trial using the chemotherapy agent 9nitro-camptothecin (9-NC), a topoisomerase inhibitor, has been conducted and although it only showed a $7 \%$ objective response rate it did demonstrate 6-month progression-free survival rate of $33 \%$ and a median time to progression of 9.9 weeks. (Chugh et al., 2005) No phase III clinical study of systemic therapy of chordomas been reported.

Other groups have attempted to investigate the effects of molecular targeted therapies as potential adjuvant treatments for low-grade chordomas. A phase II study of chordoma response to Imatinib Mesylate, a tyrosine kinase inhibitor, demonstrated a clinical benefit in 32 of 44 patients but reduction in tumour size was only observed in 7 of 44 patients. (Stacchiottis F et al., 2007)

In another study patients with PDGFR B positive inoperable or metastatic chordoma treated with imatinib mesylate, demonstrated stabilisation of the disease as a best response. (Ferraresi V et al., 2010) Other signal transduction pathways that may provide therapeutic targets include EGFR, which has been used in a single patient and showed clinical response. (Signal N et al., 2009)

Possible targets for immunotherapy include high molecular weight-melanoma associated antigen (HMW-MAA). This is expressed in over $60 \%$ of chordomas and studies have shown that this may be a useful target to apply immunotherapy to these tumours. (Schwab JH et al., 2009)

As laboratory and clinical investigations have started to reveal the genetic and molecular pathways involved in the pathogenesis of chordoma, future efforts may be focused on finding novel techniques to that can be translated into clinical practice.

\section{Prognosis}

Interpretation of published data on survival rates is difficult because of the heterogeneity of published series, small numbers of patients, short follow-up periods and difficulties in 
histological diagnoses, which has been common in earlier studies. Colli and Mefty (2001) documented a 5 -year survival of $85.9 \%$ but this series included lesions, which may actually represent chondrosarcomas, which are known to have a better prognosis. In the large series by Choi et al 2010 the median survival rate was 84-months and the mean survival was 99 months from the date of surgery with 5- and 10-year survival times 55\% and 36\% respectively. Other studies have shown similar survival rates to this with Carpentier et al. (2002) having 5- and 10-year survival rates of $80 \%$ and $65 \%$ and Forsyth et al. (1993) showing survival rates of $51 \%$ and $35 \%$ following surgery.

\section{Expert suggestions}

Craniocervical junction chordomas are unique tumours that pose significant treatment challenges. As these lesions are rare we advocate that they should be treated at the first presentation at specialist centres where patients undergo careful selection and counselling and where specialists can perform a maximal resection of the tumour whilst keeping complications to a minimum.

\section{Conclusion}

Craniovertebral junction tumours are rare tumours that can present in a number of different ways. The majority of these tumours require radical surgery followed by adjuvant radiation therapy to improve outcome. Due to the heterogeneity of published series it is not possible to compare survival outcomes between existing series. However, due to the location of these tumours the prognosis remains poor.

\section{Acknowledgements}

The authors would like to thank the Dr Maria Thom, Consultant Neuropathologist at the National Hospital for Neurology and Neurosurgery, for supplying us with the histopathological images.

\section{References}

Azzarelli A, Quagliuolo V, Cerasoli S, Zucali R, Bignami P, Mazzaferro V, Dossena G \& Gennari L. 1988. Chordoma: Natural history and treatment results in 33 cases. Journal of Surgical Oncology. 37(3):185-191.

Bhadra AK, Casey AT. 2006. Familial Chordoma. A report of two cases. The Journal of Bone $\mathcal{E}$ Joint Surgery. 88B:634-66.

Bouramas D \& Crockard A. 2003. Anterior Odontoid Resection. In Surgical Techniques for the Spine. Haher TR, Merola AA. Pp 10-15. Thieme Medical Publishers, ISBN 3131247614, New York.

Carpentier A, Polivka M, Blanquet A, Lot G, George B. 2002. Suboccipital and cervical chordomas: The value of aggressive treatment at first presentation of the disease. Journal of Neurosurgery. 97:1070-1077.

Catton C, O'Sullivan B, Bell R, Laperriere N, Cummings B, Fornasier V \& Wunder J. 1996. Chordoma: Long term follow-up after radical photon irradiation. Radiotherapy $\mathcal{E}$ Oncology. 41(1):67-72. 
Chugh R, Dunn R, Zalupski MM, Bierman JS, Sondak VK, Mace JR, Leu KM, Chandler WF \& Baker LH. 2005. Phase II study of 9-nitro-camptothecin in patients with advanced chordoma or soft tissue sarcoma. Journal of Clinical Oncology. 23(15):3597-604.

Choi D, Melcher R, Harms J, Crockard A. 2010. Outcome of 132 operations in 97 patients with chordomas of the craniocervical junction and upper cervical spine. Neurosurgery. 66(1):59-65.

Colli BO \& Al-Mefty O. 2001. Chordomas of the skull base: follow-up review and prognostic factors. Journal of Neurosurgery. 95:933-943.

Crockard HA, Heilman AE, Stevens JM. 1993. Progressive myelopathy secondary to odontoid fractures: clinical, radiological and surgical features. Journal of Neurosurgery. 78(4)579-586.

Crockard HA, Steel T, Plowman N, Singh A, Crossman J, Revesz T, Holton JL, Cheeseman A. 2002. A multidisciplinary team approach to skull base chordomas. Journal of Neurosurgery. 95:175-183.

Cummings BJ, Hodson DI, Bush RS. 1999. Chordoma: The results of megavoltage therapy. International Journal of Radiation Oncology, Biology, Physics. 9:633-642.

Cushing H. 1912. The pituitary body and its disorders. Philadelphia: JB Lippincott.

DiFrancesco LM, Cristobal A, Castillo D, Temple WJ. 2006. Extra-Axial Chordoma. Archives Pathological and Laboratory Medicine. 130:1871-74.

Eriksson B, Gunterberg B, Kindblom LG. 1981. Chordoma: A clinicopathological and prognostic study of a Swedish national series. Acta Orthopaedica Scandinavica. 52:49-58.

Ferraresi V, Nuzzo C, Zoccali C, marandino F, Vidiri A, Salducca N, Zeuli M, Giannarelli D, Cognetti F, Biagini R. 2010. Chordoma: clinical characteristics, management and prognosis of a case series of 25 patients. BMC Cancer. 22:1471-2407.

Fleming A, Keynes RJ, Tannahill D. 2001. The role of the notochord in vertebral column formation. Journal of Anatomy. 199;177-80.

Forsyth PA, Cascino TL, Shaw EG, Scheithaeur BW, O'Fallon JR, Dozier JC, Piepgras DG. 1993. Intracranial chordomas: A clinicopathological and prognostic study of 51 cases. Journal of Neurosurgery. 78:741-747.

Fuller DB \& Bloom JG. 2003. Radiotherapy for chordoma. International Journal of Radiation Oncology, Biology, Physics. 56:7-13.

Gay E, Sekhar LN, Wright DC. 1995a. Chordomas and chondrosarcomas of the cranial base. In Brain Tumours. Kaye AH, Laws ER Jr. Pp. 777-794. Churchill Livingstone, ISBN 0443048401, Edinburgh.

Gay E, Sekhar LN, Rubinstein E, Wright DC, Sen C, Janecka IP, Snyderman CH. 1995b.Chordomas and chondrosarcomas of the skull base: results and follow-up of 60 patients. Neurosurgery. 36:887-897.

Harbour JW, Lawton MT, Criscuolo GR, Holliday MJ, Mattox DE, Long DM. 1991. Clivus chordoma: A report of 12 recent cases and review of the literature. Skull Base Surgery. 1:200-206.

Kanavel AB. 1908. Bullet located between the atlas and the base of the skull: technique of removal through the mouth. Surgical Clinics of Chicago. 1:361-366.

Kassam AB, Gardner P, Snyderman C, Mintz A, Carrau R. 2005. Expanded endonasal approach: fully endoscopic, completely transnasal approach to the middle third of the clivus, petrous bone, middle cranial fossa and infratemporal fossa. Neurosurgery Focus. 15;19(1):E6.

Klingler L, Shooks J, Fiedler PN, Marney A, Butler MG. 2000. Microsatellite instability in sacral chordoma. Journal of Surgical Oncology. 73:100-3. 
McSweeney AJ \& Sholl PR. 1959. Metastatic chordoma use of mechlorethamine (nitrogen mustard) in chordoam therapy. AMA Archives of Surgery. 79:152-155.

Muzenrider JE \& Liebsch NJ. 1999. Proton beam therapy for tumours of the skull base. Strahlentherapie und Onkologie. 175(Suppl 2):57-63.

Pallini R, Maira G, Pierconti F, Falchetti ML, Alvino E, Cimino-Reale G, Fernandez E, D'Ambrosio E, Larocca LM. 2003. Chordoma of the skull base: predictors of tumour recurrence. Journal of Neurosurgery. 98(4):812-822.

Pazzaglia UE, Salisbury JR, Byers PD. 1989. Development and involution of the notochord in the human spine. Journal of the Royal Society of Medicine. 82:413-415.

Muller H. 1858. Ueber das Vorkommen von resten der chorda dorsalis bei menschen nach der geburt und uber ihr verhaltniss zu den gallertgeschwulsten am clivus. Z Ration Medic. 2:202-229.

Razis DV, Tsatsaronis A, Kyriazides I et al. 1974. Chordoma of the cervical spine treated with vincristine sulfate. Journal of Medicine. 5:274-277.

Ribbert H. 1895. Uber die experementelle Erzuegung einer Ecchondrosis physaliforia. Verh Dtsch Kong Inn Med. 13:455-464.

Rosenberg AE. 2003. Pathology of chordoma and chondrosarcoma of the axial skeleton. In: Chondromas and Chondrosarcomas of the Skull Base and Spine. Harsh GD, Janecka IP, Mankin HJ, Ojemann RG, Suit H, pp.8-15. Thieme Medical Publishers, ISBN 9783131247711, New York.

Salisbury JR, Deverell MH, Cookson JH \& Whimster WF. 1993. Three dimensional reconstruction of human embryonic notochords: clue to the pathogenesis of chordoma. Journal of Pathology. 171:59-62.

Scimeca PG, James-Herry AG, Black KS, Kahn E \& Weinblatt ME. 1996. Chemotherapeutic treatment of malignant chordoma in children. Journal of Pediatric Hematology $\mathcal{E}$ Oncology. 18:237-240.

Scwab JH, Boland PJ, Agaram NP, Socci ND, Guo T et al. 2009. Chordoma and chondrosarcoma gene profile: implications for immunotherapy. Cancer Immunology \& Immunotherapy. 58:339-349.

Sculz-Ertner D, Karger CP, Feuerhake A, Nikoghosyan A, Combs SE, Jakel O, Elder L, Scholz M \& Debus J. 2007. Effectiveness of carbon ion therapy in the treatment of skull base chordomas. International Journal of Radiation Oncology, Biology, Physics. 68:449-457.

Sen CS, Sekhar LN. 1990. An extreme lateral approach to intradural lesions of the cervical spine and foramen magnum. Neurosurgery. 27:197-204.

Singhal N, Kotasek D, Parnis FX. 2009. Response to erlotinib in a patient with treatment refractory chordoma. Anticancer Drugs. 20:953-955.

Stacchiottis FV, Ferraresi G, Grignani F, Crippa A, Messina E, Tamborini CS, Gronchi A, Casali PG. 2007. Imatinib mesylate in advanced chordoma: a multicenter phase II study. Journal of Clinical Oncology. 25:1000-1003.

Svien HJ, Baker HL, Rivers MH. 1969. Jugular foramen syndrome and allied syndromes. Neurology. 13:797-809.

Zorlu F, Gurkaynak M, Yildiz F, Oge K \& Atahan IL. 2000. Conventional external radiotherapy in the management of clival chordomas with overt residual disease. Neurological Science. 21:203-207. 
EXPUCATIVE CASES OF

CONTROVERSIAL

ISSUES IN

NEUROSURGERY

tdiced by francescos sibered

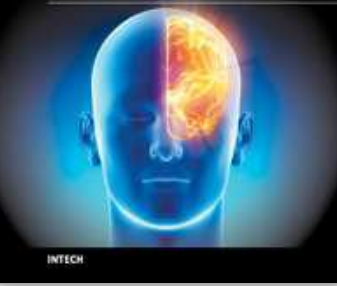

\section{Explicative Cases of Controversial Issues in Neurosurgery}

Edited by Dr. Francesco Signorelli

ISBN 978-953-51-0623-4

Hard cover, 534 pages

Publisher InTech

Published online 23, May, 2012

Published in print edition May, 2012

Neurosurgery is a rapidly developing field of medicine. Therefore, staying keeping track of the advancements in the field is paramount for trainees as well as fully trained neurosurgeons. This book, fully available online, is a part of our effort of improving availability of medical information for anyone who needs to keep up-to-date.

\section{How to reference}

In order to correctly reference this scholarly work, feel free to copy and paste the following:

Pratipal Kalsi and David Choi (2012). Craniovertebral Junction Chordomas, Explicative Cases of Controversial Issues in Neurosurgery, Dr. Francesco Signorelli (Ed.), ISBN: 978-953-51-0623-4, InTech, Available from: http://www.intechopen.com/books/explicative-cases-of-controversial-issues-in-neurosurgery/chordomas-oftthe-craniocervical-junction

\section{INTECH}

open science | open minds

\section{InTech Europe}

University Campus STeP Ri

Slavka Krautzeka 83/A

51000 Rijeka, Croatia

Phone: +385 (51) 770447

Fax: +385 (51) 686166

www.intechopen.com

\section{InTech China}

Unit 405, Office Block, Hotel Equatorial Shanghai

No.65, Yan An Road (West), Shanghai, 200040, China

中国上海市延安西路 65 号上海国际贵都大饭店办公楼 405 单元

Phone: +86-21-62489820

Fax: $+86-21-62489821$ 
(C) 2012 The Author(s). Licensee IntechOpen. This is an open access article distributed under the terms of the Creative Commons Attribution 3.0 License, which permits unrestricted use, distribution, and reproduction in any medium, provided the original work is properly cited. 